\title{
Association Between Community Social Capital and Hospital Readmission Rates
}

\author{
Amanda L. Brewster, PhD, ${ }^{1,2}$ Suhna Lee, PhD, Leslie A. Curry, PhD, ${ }^{1,2}$ and Elizabeth H. Bradley, PhD ${ }^{3}$
}

\begin{abstract}
Hospital readmissions remain frequent, and are partly attributable to patients' social needs. The authors sought to examine whether local community levels of social capital are associated with hospital readmission rates. Social capital refers to the connections among members of a society that foster norms of reciprocity and trust, which may influence the availability of support for postdischarge recovery after hospitalization. Associations between hospital-wide, risk-stratified readmission rates for hospitals in the United States $(n=4298)$ and levels of social capital in the hospitals' service areas were examined. Social capital was measured by an index of participation in associational activities and civic affairs. A multivariate linear regression model was used to adjust for hospital and community factors such as hospital financial performance, race, income, and availability of heath care services. Results showed that higher social capital was significantly associated with lower readmission rates $(P<.01)$, a finding that held across income-stratified analyses as well as sensitivity analyses that included hospital performance on process quality measures and hospital community engagement activities. A hospital is unlikely to be able to influence prevailing levels of social capital in its region, but in areas of low social capital, it may be possible for public or philanthropic sectors to buttress the types of institutions that address nonmedical causes of readmission.
\end{abstract}

Keywords: social capital, hospital readmissions, population health

\section{Introduction}

D ESPITE NATIONAL EFFORTS to reduce unplanned readmission rates, more than $15 \%$ of Medicare beneficiaries are readmitted within 30 days of hospital discharge. ${ }^{1}$ Previous research has identified several hospital-based practices that have been associated with lower risk-standardized readmission rates, such as improved discharge processes ${ }^{2-6}$ and managerial approaches within the hospital. ${ }^{7}$ These results suggest that hospital practices influence readmissions; however, results are mixed across different studies, and overall, the magnitude of effects is relatively modest. ${ }^{8}$

Increasingly, researchers have sought to understand how sociodemographic factors influence risk of hospital readmission. Recent studies have demonstrated that higher readmission rates are associated with lower income, 9,10 lower educational attainment, ${ }^{9,11}$ and nonwhite race. ${ }^{12}$ Personal social ties such as marriage ${ }^{9}$ and having family and friends nearby ${ }^{11}$ also have been linked to lower readmission rates.

Although these results have been helpful, previous empirical work has been limited in the breadth of community features examined, with no exploration of the link between readmission rates and local levels of social capital. Social capital, which is associated with a range of positive health outcomes, ${ }^{13}$ refers to the connections among members of a society that foster norms of reciprocity and trust and allow people to work together more effectively. ${ }^{13,14}$ Social capital can be conceived as a property of a community rather than an attribute of individual people. An individual person who is not particularly trusting or cooperative may still benefit from living in a community where his or her neighbors are trusting and cooperative. ${ }^{13}$ In Putnam's influential formulation, ${ }^{14,15}$ social capital is measured in terms of levels of participation in associational activities and civic affairs, as these indicators represent cooperative approaches to community issues. Because social needs exert an important influence on an individual's ability to recover outside of the hospital, ${ }^{16}$ the research team hypothesized that higher community levels of social capital may be associated with lower readmission rates.

Accordingly, the team sought to determine the association between hospital risk-stratified 30-day readmission rates

\footnotetext{
${ }^{1}$ Department of Health Policy and Management, Yale School of Public Health, New Haven, Connecticut.

${ }^{2}$ Yale Global Health Leadership Initiative, Yale University, New Haven, Connecticut.

${ }^{3}$ Office of the President, Vassar College, Poughkeepsie, New York.
} 
(RSRR) and levels of social capital, measured using an index based on Putnam's formulation of social capital, ${ }^{17}$ which has been used in prior health studies. ${ }^{18,19}$ A deeper understanding of community features that influence readmission risk, including the role of social capital, may help to identify novel levers for assisting patients with postdischarge recovery outside of the hospital, and also to calibrate expectations for the ability of hospitals to influence readmission rates.

\section{Methods}

\section{Study design and sample}

Social capital data were available for the continental United States; therefore, the research team conducted a crosssectional analysis of data from all nonfederally owned hospitals in the continental United States with publicly reported RSRRs for all-cause, hospital-wide readmission rates in the Centers for Medicare \& Medicaid Services Hospital Compare database for 2011-12. The sample consisted of 4298 hospitals. Hospitals that were missing any of the independent variables in the final model were excluded; this resulted in the exclusion of 223 hospitals, or about $5 \%$ of the sample. To link hospitals with data on their local regions the team used Hospital Service Areas (HSAs), which the Dartmouth Health Atlas delineated by assigning US zip codes to the hospital that received the greatest proportion of residents' Medicare hospitalizations. ${ }^{20}$

\section{Data and measures}

Outcome. The primary outcome was all-cause, hospitalwide RSRRs for the period of July 1, 2011 - June 30, 2012 obtained from the Hospital Compare database. ${ }^{21}$ This time period was selected to provide a 2-year lag from the data on social capital and hospital characteristics. RSRR is adjusted for patients' sex, age, and clinical risk factors. ${ }^{22,23}$

Independent variable. Social capital. For the measure of social capital the research team used 2009 values of the Social Capital Index, ${ }^{17}$ which is available at the county level for all counties within the continental United States. This standardized index was derived from principal component analysis of 4 data sources covering all US counties: voter turnout, census response rate, nonprofit organizations per capita, and associations per capita (eg, religious, civic, social, business, political, professional, labor, sports associations). The first principle component is used as the Social Capital Index. By capturing markers of civic participation (voter turnout and census participation) and markers of formal associations (nonprofit organizations and associations), the index provides a means to compare relative levels of social capital among different counties in the United States.

The research team transformed county-level data to HSAlevel data by assigning county-level data to the zip codes constituting the county. When zip codes spanned multiple counties, zip code-level values were calculated as the mean of those counties, weighted by the proportion of the zip code's population residing in each county. HSA-level data were reconstituted by taking population-weighted averages of the HSA's constituent zip codes.

Covariates. Hospital financial performance. Data on hospital financial performance were obtained from the 2006
American Hospital Directory, ${ }^{24}$ including: operating margin ratios (net income divided by total revenue), equity finance ratios (total fund balance divided by total assets), equity turnover ratios (total revenue divided by total assets), and current ratios (current assets divided by current liabilities) for each hospital.

Availability of health care resources in the HSA. Data on the availability of outpatient and inpatient care in each hospital's HSA were obtained from the Dartmouth Health Atlas, including hospital beds per 1000 residents, total physicians per 100,000 residents, and primary care physicians per 100,000 residents. The ratio of primary care physicians to total physicians was calculated.

Other hospital and community characteristics. Data on hospital characteristics were obtained from the 2010 AHA Annual Survey, ${ }^{25}$ including: census region, teaching status (defined as members of the Council of Teaching Hospitals or hospitals having an accredited residency program), hospital ownership, number of hospital beds, and urban/rural location (defined according to the 2013 urban influence code ${ }^{26}$ associated with the hospital's county). The American Communities Survey zip code-level data from 2008-2012 were used to calculate population-weighted values of median household income and mean racial composition for each HSA.

Process measures of quality. Data on key process measures of quality for heart failure, acute myocardial infarction (AMI), and pneumonia were obtained from the Hospital Compare database for the year 2012. Process measures for heart failure included the percent of patients who received evaluation of left ventricular systolic (LVS) function, were given an angiotensin converting enzyme inhibitor or angiotensin receptor blocker for LVS dysfunction, and who received discharge instructions. Process measures for AMI included the percent of patients given aspirin at arrival, given aspirin at discharge, and percent of patients treated with percutaneous coronary intervention (PCI) who received intervention within 90 minutes of arrival. Process measures for pneumonia included the percent of patients whose initial emergency room blood culture was performed prior to administration of first dose of antibiotics, and the percent of patients given the most appropriate initial antibiotics. The research team reserved these variables for sensitivity analysis because they were missing for $14 \%-66 \%$ of hospitals in the sample.

Hospital-community engagement. In order to understand the relative roles of social capital and hospital-community engagement, sensitivity analyses were conducted using hospital responses to questions about hospital-community relationships from the 2010 AHA Annual Survey. The survey included a series of 13 yes/no items (Table 1) that together describe the hospital's mission, specific contributions to community benefits and community building, and partnerships with other organizations in the community. Hospital community benefits and community building can include any activities that promote the welfare of the local population, including charity care, public health education or local economic development, among others. The research team reserved these variables for sensitivity analysis because they were incomplete for $32 \%$ of hospitals in the sample. 
Table 1. Hospital-Community Engagement Questions from the 2010 American Hospital Association Annual Survey

1. Does the hospital's mission statement include a focus on community benefit?

2. Does the hospital have a long-term plan for improving the health of its community?

3. Does the hospital have resources for its community benefit activities?

4. Does your hospital have dedicated staff to manage community benefits?

5. Does your hospital provide support for community-building activities?

6. Does your hospital make financial contributions?

7. Does your hospital partner with your local school system to offer health or wellness programs to help your community?

8. Does the hospital work with other local providers, public agencies or community representatives to conduct a health status assessment of the community?

9. Does your hospital use health status indicators to design new services or modify existing services?

10. Does your hospital work with other local providers, public agencies, or community representatives to develop a written assessment of the appropriate capacity for health services in the community?

11. If yes, has the hospital used the assessment to identify unmet health needs, excess capacity, or duplicate services in the community?

12. Does the hospital work with other providers to collect, track, and communicate clinical and health information across cooperating organizations?

13. Does the hospital, alone or with others, disseminate reports to the community on the quality and costs of health care services?

\section{Data analysis}

Multivariable linear regression was used to examine the adjusted association between the outcome RSRR and social capital. The research team adjusted for measures of financial performance, availability of health care resources in the HSA, and other hospital and community characteristics. To fit the model, preliminary analyses were conducted to narrow the 4 candidate variables representing hospital financial performance by modeling RSRR while adjusting for hospital characteristics (census region, teaching status, number of beds, ownership, and urban/rural location) and the 4 financial performance variables. Financial performance variables were retained for use in the full model if they were significant $(P<0.10)$ or if their removal changed remaining parameter estimates of other significant variables by more than $20 \%{ }^{27}$ In sensitivity analyses, the research team reestimated the final model including process measures and hospital-community engagement variables to assess how their addition might attenuate the association between social capital and RSRR.

Each hospital was assigned the community characteristics of the HSA that it served, but some HSAs included more than 1 hospital. In order to account for clustering of some hospitals within the same HSA, models were fit with clustered standard errors by HSA. The research team anticipated that the influence of social capital or other independent variables might vary by HSA income levels; therefore, the team conducted income-stratified analyses. SAS 9.4 (SAS Institute Inc., Cary, NC) was used for all analyses.

\section{Results \\ Sample characteristics}

Of the 4298 hospitals in the continental United States with data on all-cause hospital-wide readmissions, $223(5 \%)$ were excluded from the final analytic sample because they were missing data for other variables in the model. For the 4075 hospitals remaining in the final analytic sample, the mean all-cause, hospital-wide RSRR was $16.0 \%$ (Table 2).
Compared to hospitals with missing data, hospitals included in the final analytic sample had somewhat lower RSRRs and lower social capital levels.

\section{Multivariate analysis}

In fully adjusted analyses, hospitals serving HSAs with lower social capital levels had significantly higher RSRRs (Table 3). The mean RSRR of hospitals serving HSAs in the lowest quintile of social capital was 0.55 percentage points higher than the mean RSRR of hospitals in the highest quintile of social capital $(P<.01)$. Hospital financial performance also was significantly associated with RSRR, with higher operating margin ratios associated with lower RSRR $(P<.01)$. Household income and racial composition of the HSA were significantly associated with RSRR. Having fewer hospital beds per 1000 residents and physicians per 100,000 residents also were associated with lower RSRRs. Hospital teaching status and share of physicians in the HSA who were primary care physicians were not significantly associated with RSRR.

Income-stratified results. In income-stratified results, the significant relationship between lower social capital and higher RSRR was evident within high-, medium-, and lowincome strata (Table 4). The relationships between RSRR and several other variables varied by income level, however. Notably, hospital operating margin ratio was significantly associated with RSRR in the highest $(P<.01)$ and middle $(P=.04)$ income strata, but not in the lowest income stratum.

Sensitivity analyses. The magnitude and significance of associations between RSRR and social capital, hospital financial performance, and other independent variables remained largely unchanged when hospital process measures of quality and hospital-community engagement measures were added as covariates; however, several of the measures added in sensitivity analyses were associated with RSRR in the fully adjusted models. Three hospital process measures were associated with lower RSRR: percent of heart failure 
Table 2. Characteristics of Hospitals and Hospital Service Areas in Which They Are Located

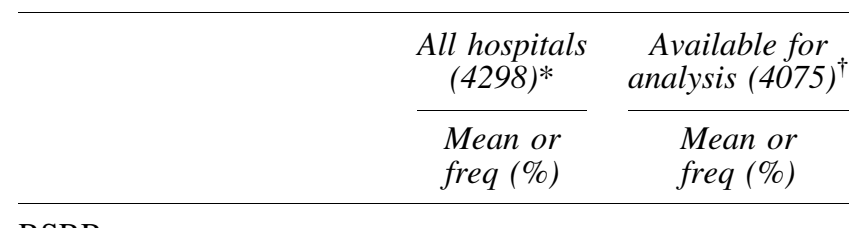

\section{RSRR}

Mean all-cause RSRR

15.99

16.00

Social capital

Social capital index

$-0.34$

$-0.33$

Census region

New England

Mid-Atlantic

East North Central

West North Central

South Atlantic

East South Central

West South Central

Mountain

Pacific

Teaching status

Teaching

Nonteaching

Hospital size (\# beds)

$<200$

200-399

400-599

$\geq 600$

Hospital ownership

Government

(Nonfederal)

Private for Profit

Private Nonprofit

Hospital finances

Operating Margin Ratio

Urban/rural location

Rural

Suburban

Urban

$$
4.2
$$

8.9

15.9

14.5

15.0

8.6

14.4

8.1

10.5

4.3

9.3

16.1

14.5

14.9

9.0

14.3

7.6

10.0

18.3

18.2

81.7

81.8

69.4

20.3

6.3

4.0

69.2

20.5

6.3

4.1

22.1

22.6

17.1

60.8

16.7

(0.04

60.7

0.04

0.04

17.3

23.1

59.6

17.3

23.6

Household income

Median household income

46,698

46,547

Race

Mean $\%$ white

Health care supply

Mean hospital beds/ 1000 residents

Mean physicians/ 100,000 residents

Mean ratio PCPs/total physicians

$\begin{array}{rr}80.1 & 80.3 \\ 2.9 & 2.9 \\ 197.6 & 197.6 \\ 0.37 & 0.37\end{array}$

*All hospitals with all-cause, hospital-wide RSRR data.

${ }^{\dagger}$ All hospitals with non-missing data for all model variables (complete cases). Four hospitals were missing social capital data and 219 hospitals were missing operating margin ratio. These 223 hospitals (5\% of the sample) were excluded from analysis.

$\mathrm{PCP}$, primary care physician; RSRR, risk-stratified readmission rate.

patients who received evaluation of LVS function, percent of AMI patients given aspirin at discharge, and percent of AMI patients treated with PCI who received intervention within 90 minutes of arrival. Two hospital-community engagement measures were associated with lower RSRR: use
Table 3. Fully Adjusted Model of Hospital-Wide RisK-STRATIFIED READMISSION RATES

\begin{tabular}{|c|c|c|}
\hline Parameter & Estimate & $\mathrm{P}$ \\
\hline $\begin{array}{c}\text { Social capital } \\
\text { Quintile } 1 \\
\text { Quintile } 2 \\
\text { Quintile } 3 \\
\text { Quintile } 4 \\
\text { Quintile } 5\end{array}$ & $\begin{array}{l}0.55(0.39,0.71) \\
0.29(0.13,0.45) \\
0.15(0.03,0.28) \\
0.10(-0.01,0.21)\end{array}$ & $\begin{array}{l}0.00 \\
0.00 \\
0.02 \\
0.07\end{array}$ \\
\hline $\begin{array}{l}\text { Census Region } \\
\text { New England } \\
\text { Mid-Atlantic } \\
\text { East North Central } \\
\text { West North Central } \\
\text { South Atlantic } \\
\text { East South Central } \\
\text { West South Central } \\
\text { Mountain } \\
\text { Pacific }\end{array}$ & $\begin{array}{c}0.66(0.47,0.86) \\
0.95(0.74,1.16) \\
0.58(0.38,0.78) \\
0.31(0.14,0.49) \\
0.37(0.22,0.52) \\
0.49(0.34,0.65) \\
0.1(-0.06,0.25) \\
0.01(-0.14,0.16)\end{array}$ & $\begin{array}{l}0.00 \\
0.00 \\
0.00 \\
0.00 \\
0.00 \\
0.00 \\
0.22 \\
0.90\end{array}$ \\
\hline $\begin{array}{l}\text { Teaching status } \\
\text { Teaching }\end{array}$ & $0.04(-0.07,0.16)$ & 0.46 \\
\hline $\begin{array}{l}\text { Hospital size (\# beds) } \\
\quad<200 \\
200-399 \\
400-599 \\
\geq 600\end{array}$ & $\begin{array}{l}-0.31(-0.53,-0.08) \\
-0.26(-0.47,-0.04) \\
-0.19(-0.43,0.05)\end{array}$ & $\begin{array}{l}0.01 \\
0.02 \\
0.11\end{array}$ \\
\hline $\begin{array}{l}\text { Hospital ownership } \\
\text { Government (Nonfederal) } \\
\text { Private for Profit } \\
\text { Private Nonprofit }\end{array}$ & $\begin{array}{c}0.11(0.04,0.19) \\
0.2(0.1,0.3)\end{array}$ & $\begin{array}{l}0.00 \\
0.00\end{array}$ \\
\hline $\begin{array}{l}\text { Urban/rural location } \\
\text { Rural } \\
\text { Suburban } \\
\text { Urban }\end{array}$ & $\begin{array}{l}0.15(0.05,0.25) \\
0.04(-0.05,0.13)\end{array}$ & $\begin{array}{l}0.00 \\
0.42\end{array}$ \\
\hline $\begin{array}{l}\text { Hospital finances } \\
\text { Operating Margin Ratio }\end{array}$ & $-0.42(-0.64,-0.2)$ & 0.00 \\
\hline $\begin{array}{l}\text { Household income } \\
\text { Quintile } 1 \\
\text { Quintile } 2 \\
\text { Quintile 3 } \\
\text { Quintile } 4 \\
\text { Quintile 5 }\end{array}$ & $\begin{aligned} 0.21 & (0.08,0.34) \\
0.09 & (-0.04,0.22) \\
-0.02 & (-0.16,0.12) \\
-0.06 & (-0.18,0.06)\end{aligned}$ & $\begin{array}{l}0.00 \\
0.17 \\
0.75 \\
0.31\end{array}$ \\
\hline $\begin{array}{l}\text { Percent white race } \\
\text { Quintile } 1 \\
\text { Quintile } 2 \\
\text { Quintile } 3 \\
\text { Quintile } 4 \\
\text { Quintile } 5\end{array}$ & $\begin{array}{c}0.35(0.18,0.52) \\
0.20(0.07,0.33) \\
0.00(-0.11,0.1) \\
-0.07(-0.16,0.02)\end{array}$ & $\begin{array}{l}0.00 \\
0.00 \\
0.94 \\
0.10\end{array}$ \\
\hline $\begin{array}{l}\text { Heath care supply } \\
\text { Hospital beds/1000 }\end{array}$ & $0.12(0.09,0.15)$ & 0.00 \\
\hline $\begin{array}{l}\text { residents } \\
\text { Physicians/100,000 } \\
\text { residents }\end{array}$ & $.002(.001, .003)$ & 0.00 \\
\hline $\begin{array}{l}\text { Ratio PCPs/total } \\
\text { physicians }\end{array}$ & $-0.13(-0.76,0.51)$ & 0.70 \\
\hline
\end{tabular}

PCP, primary care physician.

of a community assessment to identify unmet health needs or excess capacity in the community, and making financial contributions for community-building activities. The total number of community engagement activities reported by the hospitals was negatively associated with RSRR. 
Table 4. Fully Adjusted Model of Hospital-Wide Risk-Stratified Readmission Rates, Stratification by Median Household InCOME

\begin{tabular}{|c|c|c|c|c|c|c|}
\hline \multirow[b]{3}{*}{ Parameter } & \multicolumn{2}{|l|}{ Low income } & \multicolumn{2}{|l|}{ Middle income } & \multicolumn{2}{|l|}{ High income } \\
\hline & \multicolumn{2}{|l|}{$n=1432$} & \multicolumn{2}{|l|}{$n=1434$} & \multicolumn{2}{|l|}{$n=1432$} \\
\hline & Estimate & $\mathrm{P}$ & Estimate & $\mathrm{P}$ & Estimate & $\mathrm{P}$ \\
\hline \multicolumn{7}{|l|}{ Social capital } \\
\hline Quintile 1 & $0.57(0.34,0.79)$ & 0.00 & $0.53(0.3,0.75)$ & 0.00 & $0.61(0.29,0.92)$ & 0.00 \\
\hline Quintile 2 & $0.19(0,0.39)$ & 0.05 & $0.23(-0.02,0.48)$ & 0.07 & $0.41(0.12,0.7)$ & 0.01 \\
\hline Quintile 3 & $0.24(0.06,0.42)$ & 0.01 & $0.03(-0.15,0.21)$ & 0.71 & $0.21(-0.07,0.48)$ & 0.15 \\
\hline Quintile 4 & $0.07(-0.08,0.23)$ & 0.36 & $-0.05(-0.22,0.11)$ & 0.52 & $0.31(0.07,0.56)$ & 0.01 \\
\hline Quintile 5 & & & & & & \\
\hline \multicolumn{7}{|l|}{ Census Region } \\
\hline New England & $0.15(-0.15,0.45)$ & 0.33 & $0.76(0.35,1.18)$ & 0.00 & $0.87(0.59,1.14)$ & 0.00 \\
\hline Mid-Atlantic & $0.78(0.31,1.25)$ & 0.00 & $1.08(0.77,1.39)$ & 0.00 & $1(0.73,1.27)$ & 0.00 \\
\hline East North Central & $0.42(0.16,0.68)$ & 0.00 & $0.6(0.28,0.93)$ & 0.00 & $0.63(0.32,0.93)$ & 0.00 \\
\hline West North Central & $0.13(-0.12,0.39)$ & 0.31 & $0.21(-0.08,0.5)$ & 0.15 & $0.49(0.2,0.79)$ & 0.00 \\
\hline South Atlantic & $0.3(0.09,0.51)$ & 0.01 & $0.2(-0.06,0.46)$ & 0.13 & $0.66(0.37,0.95)$ & 0.00 \\
\hline East South Central & $0.45(0.22,0.68)$ & 0.00 & $0.43(0.15,0.71)$ & 0.00 & $0.75(0.4,1.11)$ & 0.00 \\
\hline West South Central & $0.27(0.05,0.5)$ & 0.02 & $-0.02(-0.28,0.24)$ & 0.88 & $-0.11(-0.33,0.12)$ & 0.36 \\
\hline Mountain & $-0.05(-0.3,0.19)$ & 0.67 & $-0.09(-0.35,0.17)$ & 0.49 & $0.16(-0.09,0.41)$ & 0.21 \\
\hline Pacific & & & & & & \\
\hline \multicolumn{7}{|l|}{ Teaching status } \\
\hline Teaching & $0.41(0.07,0.75)$ & 0.02 & $-0.14(-0.31,0.02)$ & 0.09 & $0(-0.16,0.16)$ & 0.99 \\
\hline \multicolumn{7}{|l|}{ Hospital size } \\
\hline$<200$ & $-0.28(-0.78,0.21)$ & 0.26 & $-0.24(-0.6,0.12)$ & 0.19 & $-0.3(-0.63,0.04)$ & 0.08 \\
\hline $200-399$ & $-0.25(-0.75,0.25)$ & 0.33 & $-0.22(-0.59,0.14)$ & 0.23 & $-0.23(-0.53,0.08)$ & 0.14 \\
\hline $400-599$ & $-0.12(-0.73,0.48)$ & 0.69 & $-0.04(-0.43,0.34)$ & 0.82 & $-0.28(-0.6,0.05)$ & 0.09 \\
\hline$\geq 600$ & & & & & & \\
\hline \multicolumn{7}{|l|}{ Hospital ownership } \\
\hline $\begin{array}{l}\text { Government } \\
\text { (Nonfederal) }\end{array}$ & $-0.03(-0.15,0.09)$ & 0.58 & $0.11(-0.01,0.22)$ & 0.06 & $0.41(0.24,0.59)$ & 0.00 \\
\hline Private for Profit & $0.16(0,0.32)$ & 0.06 & $0.24(0.07,0.41)$ & 0.01 & $0.2(0.03,0.38)$ & 0.02 \\
\hline Private Nonprofit & & & & & & \\
\hline \multicolumn{7}{|l|}{ Hospital finances } \\
\hline $\begin{array}{l}\text { Operating Margin } \\
\text { Ratio }\end{array}$ & $-0.19(-0.59,0.21)$ & 0.35 & $-0.33(-0.64,-0.02)$ & 0.04 & $-0.69(-1.14,-0.25)$ & 0.00 \\
\hline \multicolumn{7}{|l|}{ Urban/rural location } \\
\hline Rural & $0.16(0,0.32)$ & 0.04 & $0.15(0,0.3)$ & 0.05 & $0.14(-0.11,0.39)$ & 0.27 \\
\hline Suburban & $-0.01(-0.14,0.12)$ & 0.88 & $0.1(-0.03,0.24)$ & 0.14 & $0.31(0.08,0.53)$ & 0.01 \\
\hline Urban & & & & & & \\
\hline \multicolumn{7}{|l|}{ Percent white race } \\
\hline Quintile 1 & $0.16(-0.04,0.36)$ & 0.11 & $0.71(0.36,1.06)$ & 0.00 & $0.46(0.18,0.73)$ & 0.00 \\
\hline Quintile 2 & $0.07(-0.12,0.26)$ & 0.48 & $0.37(0.13,0.61)$ & 0.00 & $0.36(0.12,0.6)$ & 0.00 \\
\hline Quintile 3 & $-0.18(-0.36,0)$ & 0.05 & $0.11(-0.06,0.27)$ & 0.21 & $0.18(-0.02,0.38)$ & 0.08 \\
\hline Quintile 4 & $-0.12(-0.27,0.03)$ & 0.13 & $-0.02(-0.15,0.11)$ & 0.80 & $0.02(-0.16,0.2)$ & 0.84 \\
\hline Quintile 5 & & & & & & \\
\hline \multicolumn{7}{|l|}{ Health care supply } \\
\hline $\begin{array}{l}\text { Hospital beds/1000 } \\
\text { residents }\end{array}$ & $0.1(0.06,0.15)$ & 0.00 & $0.15(0.11,0.2)$ & 0.00 & $0.13(0.06,0.2)$ & 0.00 \\
\hline $\begin{array}{l}\text { Physicians/100,000 } \\
\text { residents }\end{array}$ & $0.002(0,0.003)$ & 0.01 & $0.002(0,0.003)$ & 0.03 & $0.001(0,0.003)$ & 0.13 \\
\hline $\begin{array}{l}\text { Ratio PCPs/total } \\
\text { physicians }\end{array}$ & $-0.7(-1.61,0.21)$ & 0.13 & $0.37(-0.56,1.3)$ & 0.43 & $-0.19(-1.54,1.15)$ & 0.78 \\
\hline
\end{tabular}

$\mathrm{PCP}$, primary care physician.

\section{Discussion}

This study found that social capital was significantly associated with RSRR. The association remained significant even after adjusting for financial performance, the availability of hospital beds and physicians in the HSA, and local so- cioeconomic context. Put in terms of the national distribution of hospital-wide RSRR, the .55 percentage point difference between hospitals in the highest and lowest quintiles of social capital is equivalent to moving from the median RSRR performance down to the $25^{\text {th }}$ percentile or up to the $75^{\text {th }}$ percentile. ${ }^{1}$ Given the difficulty of isolating internal processes 
of hospitals that are consistently associated with RSRR, the present study findings offer another perspective - identifying that community-based resources and hospital-community partnerships may be critical. Although this is consistent with previous results, ${ }^{9-12}$ the present findings extend previous work by examining a broader set of community resources in models adjusted for a broader range of hospital features.

\section{Social capital: potential mechanisms of action}

The mechanisms by which social capital influences RSRR cannot be determined from the data; however, other literature suggests potential pathways. Prior literature on the positive relationship between social capital and health suggests that community-level mechanisms as well as individuallevel mechanisms likely are involved. ${ }^{28}$ The present study measure of social capital focuses on associational activities and civic participation. To the extent that some nonprofit organizations and associations (eg, churches, elder service organizations) provide charitable services for vulnerable individuals in the community, the association between social capital and RSRR may reflect greater support for services that address social determinants of health such as food, housing, and income support. ${ }^{29,30}$ Populations that are more engaged with civic affairs also may influence health care and social services organizations, making these services more responsive to community needs and thus better able to prevent hospital readmissions. Prior research has demonstrated that social capital influences the ability of community representatives on hospital governing boards to influence provision of communityoriented services, ${ }^{31}$ and that social capital also influences integration of social services with health care. ${ }^{32}$

In addition to influencing hospital readmission through the community-level processes described, the norms of trust and reciprocity represented by social capital also foster social network ties for individuals. ${ }^{33}$ Neighbor-to-neighbor assistance to address social needs may contribute to avoidance of readmissions. Furthermore, individuals with more interpersonal relationships have better health and lower mortality rates $^{34-36}$; therefore, communities that encourage formation of social ties could be expected to display better aggregate measures of health status such as readmissions rates.

\section{Hospital financial performance}

This study is the first to examine the relationship between hospital operating margin ratio and RSRR, and found that higher hospital operating margins were associated with lower RSRRs. Financial strain may lead to fewer staff available to assist with discharge planning, lack of time to establish relationships with community-based providers, and absence of funding to support care transitions programs, all of which could elevate readmissions risk. The fact that operating margin ratio was significantly associated with RSRR only in higher income areas suggests that readmissions in higher income areas may be more attributable to hospital factors, whereas readmissions in lower income areas may have more do to with social challenges outside of the hospital.

\section{Hospital-community engagement}

Findings in the sensitivity analyses demonstrating an association between hospital-community engagement activities and RSRR suggest that hospital-community links may assist in transitions of care. Although this analysis was missing $32 \%$ of the hospitals in the full sample, it still included 2771 hospitals across the United States. The research team does not have details on the types of organizations that hospitals worked with but they are likely diverse, as hospital-community benefits and community building can include activities such as charity care, coalition building, community health advocacy, workforce development, and support for housing, economic development, and the environment. ${ }^{37}$ Hospital participation in Accountable Care Organizations and related programs may further encourage ties between hospitals and other community organizations, ${ }^{38}$ making the impact of these emerging links an important area for future study.

These results should be interpreted in light of several limitations. First, cross-sectional associations cannot be used to infer causality, and this study only involves data at the ecological level; it would be helpful to follow up these results with multilevel data at both patient and HSA level. Still, these results from a nationwide sample of hospitals corroborate smaller scale qualitative observations on the relationship between community resources and readmissions ${ }^{7,39}$ and highlight this nexus as an important area for further study. Second, $5 \%$ of hospitals with reported RSRR values were missing other data required for the model and therefore could not be included in the analysis. The research team believes the missing data likely biased the key findings toward the null, however, because hospitals with missing data also had significantly lower social capital and higher RSRR than hospitals included in the analysis, so removing these observations would only weaken the observed inverse relationship found between social capital and RSRR. Third, the team did not have data on all community-level health resources - such as public health infrastructure or home health services - that could be related to social capital and hospital readmissions, although the team did adjust for availability of hospital, physician, and primary care resources.

\section{Conclusion}

In conclusion, these results suggest that social capital is associated with lower RSRR, providing additional insight into the mechanisms by which community resources influence readmissions. A hospital is unlikely to be able to influence prevailing levels of social capital in its region, but in areas of low social capital, it may be possible for the public sector to buttress the types of institutions that address nonmedical causes of readmission. For example, investment in formal social services such as income, food, and housing supports may provide a safety net for the most vulnerable recently hospitalized patients. Hospitals have been advised to build relationships with post-acute providers as a strategy to reduce hospital readmissions. ${ }^{40}$ The results suggest that relationships between hospitals and other community organizations matter as well. Hospitals seeking to reduce readmissions rates might benefit from making strategic investments in strengthening links with their communities more broadly.

\section{Author Disclosure Statement}

The authors declare that there are no conflicts of interest. This research was supported by a grant from The Commonwealth Fund, New York, NY. 


\section{References}

1. Centers for Medicare \& Medicaid Services. Medicare Hospital Quality Chartbook. Centers for Medicare \& Medicaid Services; 2015. https://www.cms.gov/medicare/quality-initiativespatient-assessment-instruments/hospitalqualityinits/outcomeme asures.html Accessed April 25, 2018.

2. Coleman E, Parry C, Chalmers S, Min S. The care transitions intervention: results of a randomized controlled trial. Arch Intern Med 2006;166:1822-1828.

3. Naylor, Brooten D, Campbell R, et al. Comprehensive discharge planning and home follow-up of hospitalized elders: a randomized clinical trial. JAMA 1999;281:613-620.

4. Bradley EH, Sipsma H, Horwitz LI, et al. Hospital strategy uptake and reductions in unplanned readmission rates for patients with heart failure: a prospective study. J Gen Intern Med 2014;30:605-611.

5. Rice YB, Barnes CA, Rastogi R, Hillstrom TJ, Steinkeler CN. Tackling 30-day, all-cause readmissions with a patientcentered transitional care bundle. Popul Health Manag 2015; 19:56-62.

6. Budlong $\mathrm{H}$, Brummel A, Rhodes A, Nici H. Impact of comprehensive medication management on hospital readmission rates. Popul Health Manag [Epub ahead of print]; DOI:10.1089/pop.2017.0167

7. Brewster AL, Cherlin EJ, Ndumele CD, et al. What works in readmissions reduction: how hospitals improve performance. Med Care 2016;54:600-607.

8. Hansen L, Young RS, Hinami K, Leung A, Williams MV. Interventions to reduce 30-day rehospitalization: a systematic review. Ann Intern Med 2011;155:520-528.

9. Herrin J, St. Andre J, Kenward K, Joshi MS, Audet A-MJ, Hines SC. Community factors and hospital readmission rates. Health Serv Res 2015;50:20-39.

10. Calvillo-King L, Arnold D, Eubank KJ, et al. Impact of social factors on risk of readmission or mortality in pneumonia and heart failure: systematic review. J Gen Intern Med 2013;28:269-282.

11. Barnett M, Hsu J, McWilliams J. Patient characteristics and differences in hospital readmission rates. JAMA Intern Med 2015;175:1803-1812.

12. Joynt KE, Jha AK. Who has higher readmission rates for heart failure, and why? Implications for efforts to improve care using financial incentives. Circ Cardiovasc Qual Outcomes 2011;4:53-59.

13. Kawachi I, Subramanian SV, Kim D. Social capital and health. In: Kawachi I, Subramanian SV, Kim D, eds. Social capital and health. Springer New York; 2008:1-26.

14. Putnam RD. Bowling alone: the collapse and revival of American Community. New York: Simon and Schuster, 2001.

15. Putnam RD. Tuning in, tuning out: the strange disappearance of social capital in America. PS: Political Sci Politics 1995;28:664-683.

16. Robin M. Social support and patient adherence to medical treatment: a meta-analysis. Health Psychol 2004;23:207218.

17. Rupasingha A, Goetz SJ, Freshwater D. The production of social capital in US counties. J Socio Econ 2006;35: 83-101.

18. Chetty R, Stepner M, Abraham S, et al. The association between income and life expectancy in the United States, 2001-2014. JAMA 2016;315:1750-1766.
19. Yang T-C, Teng H-W, Haran M. The impacts of social capital on infant mortality in the U.S.: a spatial investigation. Appl Spat Anal 2009;2:211-227.

20. Dartmouth Atlas of Health Care. Appendix on the Geography of Health Care in the United States. 1999. www .dartmouthatlas.org/downloads/methods/geogappdx.pdf Accessed April 25, 2018.

21. Centers for Medicare \& Medicaid Services. Hospital Compare Database. 2017. https://data.medicare.gov/browse/embed?\&\& category $=$ Hospital+Compare \&custom_class=embeddedinline \&limit $=10 \& \operatorname{tags}=\&$ view_type $=$ rich Accessed April 25, 2018.

22. Keenan PS, Normand S-LT, Lin Z, et al. An administrative claims measure suitable for profiling hospital performance on the basis of 30-day all-cause readmission rates among patients with heart failure. Circ Cardiovasc Qual Outcomes 2008;1:29-37.

23. Krumholz HM, Lin Z, Drye EE, et al. An administrative claims measure suitable for profiling hospital performance based on 30-day all-cause readmission rates among patients with acute myocardial infarction. Circ Cardiovasc Qual Outcomes 2011;4:243-252.

24. American Hospital Directory. American hospital directory. Louisville, KY: American Hospital Directory, Inc., 2006.

25. American Hospital Association. American Hospital Association annual survey of hospitals. Chicago, IL: American Hospital Association, 2010.

26. USDA Economic Research Service. Urban Influence Codes. 2013. www.ers.usda.gov/data-products/urban-influence-codes/ documentation.aspx Accessed May 17, 2016.

27. Maldonado G, Greenland S. Simulation study of confounder-selection strategies. Am J Epidemiol 1993;138: 923-936.

28. Kawachi I, Kim D, Coutts A, Subramanian SV. Commentary: reconciling the three accounts of social capital. Int $\mathbf{J}$ Epidemiol 2004;33:682-690.

29. McGinnis JM, Williams-Russo P, Knickman JR. The case for more active policy attention to health promotion. Health Aff 2002;21:78-93.

30. Taylor LA, Tan AX, Coyle CE, et al. Leveraging the social determinants of health: what works? PLoS One 2016;11: $\mathrm{e} 0160217$.

31. Lee S-YD, Chen WL, Weiner BJ. Communities and hospitals: social capital, community accountability, and service provision in U.S. community hospitals. Health Serv Res 2004;39: 1487-1508.

32. Rosenheck R, Morrissey J, Lam J, et al. Service delivery and community: social capital, service systems integration, and outcomes among homeless persons with severe mental illness. Health Serv Res 2001;36:691-710.

33. Kawachi I, Kennedy BP, Glass R. Social capital and selfrated health: a contextual analysis. Am J Public Health 1999; 89:1187-1193.

34. Kawachi I, Colditz GA, Ascherio A, et al. A prospective study of social networks in relation to total mortality and cardiovascular disease in men in the USA. J Epidemiol Community Health 1996;50:245-251.

35. Holt-Lunstad J, Smith TB, Layton JB. Social relationships and mortality risk: a meta-analytic review. PLoS Med 2010; 7:e1000316.

36. Yokobayashi K, Kawachi I, Kondo K, et al. Association between social relationship and glycemic control among 
older Japanese: JAGES cross-sectional study. PLoS One 2017; 12:e0169904.

37. Internal Revenue Service. Instructions for schedule H (Form 990). 2015. https://www.irs.gov/pub/irs-pdf/i990sh.pdf Accessed May 20, 2016.

38. Fraze T, Lewis VA, Rodriguez HP, Fisher ES. Housing, transportation, and food: how ACOs seek to improve population health by addressing nonmedical needs of patients. Health Aff (Millwood) 2016;35:2109-2115.

39. Brewster AL, Curry LA, Cherlin EJ, Talbert-Slagle K, Horwitz LI, Bradley EH. Integrating new practices: a qualitative study of how hospital innovations become routine. Implement Sci 2015;10:168.
40. Institute for Healthcare Improvement. State Action on Avoidable Rehospitalizations. 2014. www.ihi.org/offerings/ Initiatives/PastStrategicInitiatives/STAAR/Pages/default.aspx Accessed April 25, 2018.

Address correspondence to: Amanda L. Brewster, PhD Department of Health Policy and Management Yale School of Public Health 60 College Street New Haven, CT 06519

E-mail: amanda.brewster@yale.edu 